\title{
Desafios do multiprofissionalismo para a redução de danos em Centros de Atenção Psicossocial Álcool e outras Drogas
}

\section{Multi-professionalism related challenges in the implementation of harm reduction strategies at the Center for Psychosocial} Attention to Users of Alcohol and Other Drugs

\section{Roberto Rocha C. Pires ${ }^{\mathrm{a}}$}

(D) https://orcid.org/0000-0001-9392-949X

E-mail: roberto. piresळipea.gov.br

Maria Paula Gomes dos Santos ${ }^{\mathrm{a}}$

(D) https://orcid.org/0000-0001-8930-3179

E-mail: mariapaula.santosळipea.gov.br

anstituto de Pesquisa Econômica Aplicada. Brasília, DF, Brasil.

\section{Correspondência}

Roberto Rocha C. Pires

SBS Qd. I BI. J, Ed. BNDES, sala I.216. Brasília, DF, Brasil. CEP 70076-900.

\section{Resumo}

O artigo aborda a implementação da estratégia de Redução de Danos (RD) por equipes multiprofissionais nos Centros de Atenção Psicossocial Álcool e outras Drogas (Caps AD) do Distrito Federal. A partir dos aportes teóricos dos estudos sobre implementação de políticas públicas e da sociologia das profissões, buscou-se refletir sobre as implicações do multiprofissionalismo para a tradução da RD em ações práticas junto aos usuários dos serviços. Realizou-se pesquisa de campo nas sete unidades de Caps AD do Distrito Federal, onde as atividades cotidianas foram observadas e profissionais foram entrevistados. A análise revelou que: (1) há variação substantiva na forma como os profissionais atuantes nos Caps $\mathrm{AD}$ interpretam e praticam a $\mathrm{RD}$; (2) suas diferentes formas de entendimento e ação associam-se à formação profissional em distintos campos de conhecimento (psicossocial versus biomédico); e (3) estas divergências podem resultar em conflitos entre profissionais e implicar consequências negativas para os usuários dos serviços. Discute-se, também, os meios encontrados pelas gerências para a gestão e mitigação destas implicações. Os achados contribuem para reflexões mais amplas sobre os desafios que se impõem à sustentabilidade do modelo de atenção proposto para os Caps AD.

Palavras-chave: Multiprofissionalismo; Implementação de Políticas Públicas; Profissões; Caps AD; Redução de Danos. 
Abstract

The article focuses on the implementation of the Harm Reduction strategy by multiprofessional teams in the Centers for Psychosocial Attention to Users of Alcohol and other Drugs (CAPS AD) at the Brazilian Federal District. Based on theoretical propositions from the fields of policy implementation and sociology of professions, it sought to reflect upon the implications of different professional perspectives about the concept of Harm Reduction, and its translation into practice, for the aims of the Ministry of Health Care Policy for Alcohol and Other Drugs Users and its beneficiaries. Our study is supported by empirical research involving qualitative fieldwork on the seven units of CAPS AD in the Federal District. Our findings suggest that: (1) there is substantive variation in the way CAPS AD professionals interpret and practice harm reduction principles; (2) this variation is associated with professional education in distinct fields of knowledge (psychosocial versus biomedical); and (3) divergences among professionals may result in conflicts and produce negative consequences for service users. We also discuss the means by which service managers seek to mitigate those negative implications. These findings contribute to broader reflections on the challenges for sustainability of the Caps AD model.

Keywords: Multiprofessionalism; Policy Implementation; Occupations; Caps AD; Harm Reduction.

\section{Introdução}

Uma das diretrizes que orientam o atendimento especializado em transtornos pelo uso do álcool e outras drogas, no âmbito do Sistema Único de Saúde (SUS), é o multiprofissionalismo das equipes (Brasil, 2004). Esta diretriz já pautava os serviços públicos de saúde mental instituídos pela Reforma Psiquiátrica ${ }^{1}$ - os Centros de Atenção Psicossocial (Caps) -, dos quais são tributários os serviços de atenção a usuários de álcool e outras drogas (Caps AD), integrantes das Redes de Atenção Psicossocial (Raps), ${ }^{2}$ como dispositivos estratégicos da articulação intersetorial, territorial e comunitária.

Dentre as mudanças promovidas por esta Reforma, duas delas merecem aqui destaque: (1) o deslocamento do locus do cuidado, antes prestado por instituições hospitalares fechadas, para serviços de atenção de base comunitária; e (2) a substituição de uma perspectiva eminentemente médica sobre o sofrimento mental, centrada no corpo do indivíduo, para o modelo de atenção psicossocial, o qual pretende abarcar toda a experiência subjetiva da pessoa que sofre. Neste sentido, a atenção psicossocial requer o trabalho de equipes multiprofissionais, integradas não só por profissionais de saúde - médicos, psicólogos, enfermeiros e farmacêuticos - mas também por profissionais de serviço social, terapia ocupacional, musicoterapeutas, artistas, educadores, entre outros. O pressuposto que norteia esta prescrição é o de que o intercâmbio de saberes, em atos de cuidado conjuntos, contribui para a promoção, pelos serviços, de "uma ação integral que vise ao sujeito como existênciasofrimento" (Costa-Rosa, 20oo, p. 157).

O presente artigo busca refletir sobre a produção multiprofissional do cuidado nos Caps AD do Distrito Federal (DF), particularmente no que diz respeito à implementação da redução de danos (RD) - estratégia de cuidado, também prevista nos documentos formais da Política

\footnotetext{
1 Lei n ${ }^{0} 10.216 / 2001$, que "dispõe sobre a proteção e os direitos das pessoas portadoras de transtornos mentais e redireciona o modelo assistencial em saúde mental” (Brasil, 2001).

2 A Raps foi formalmente criada em 2011 (Portaria/GM n 3 3.088) para cumprir o papel de uma rede de saúde mental integrada, destinada a atender as pessoas em sofrimento mental e com demandas decorrentes do consumo de álcool, crack e outras drogas (Brasil, 2011).
} 
do Ministério da Saúde para a Atenção Integral a Usuários de Álcool e Outras Drogas (Pauad) (Brasil, 2004).

O princípio da RD deve comparecer nos serviços de saúde como uma ética do cuidado a direcionar as diversas ações clínicas - antes que um roteiro prescritivo e fechado de práticas predefinidas. O objetivo da RD é mitigar prejuízos decorrentes do consumo de álcool e outras drogas, contrastando com terapêuticas tradicionais usualmente aplicadas. Também não se adota a abstinência como foco principal ou exclusivo do cuidado, ainda que não se oponha a ela. Trata-se de uma proposta de "cuidado para além das drogas", que prioriza o engajamento dos usuários num projeto de autocuidado e reinserção social, o qual, no entanto, preserve sua autonomia decisória e promova sua capacidade de autorregulação (Brasil, 2004; Ferreira, 2018; Petuco, 2014).

A pesquisa orientou-se pelos aportes teóricos dos estudos de implementação de políticas públicas, inspirando-se ainda nos achados da sociologia das profissões. Os estudos de implementação há muito vêm demonstrando que colocar políticas públicas em ação requer o envolvimento de uma multiplicidade de atores, procedimentos e (inter)ações que, longe de serem neutros, influenciam e transformam os conteúdos e resultados da ação governamental (Hill; Hupe, 2014; Pressman; Wildavsky, 1973). Uma das vertentes dessa literatura privilegia o olhar sobre os agentes de linha de frente - trabalhadores na base da pirâmide hierárquica dos serviços públicos - e suas ações, comportamentos e relações com os usuários destes serviços. Estes agentes, chamados por Lipsky (1980) de streetlevel bureaucrats, frequentemente exercem suas funções sob condições marcadas pela ambiguidade normativa, escassez de recursos, abundância de demandas, e pela necessidade de decidir e agir imediatamente em situações específicas. Consequentemente, acabam gozando de algum poder discricionário, na tradução de diretrizes gerais da política pública - como a RD - em ações concretas junto aos usuários dos serviços. Diante de dificuldades para pôr em prática os comandos legais, os funcionários da linha de frente exercem agência, por meio da reinterpretação e da definição de cursos de ação específicos nas situações concretas que enfrentam no seu cotidiano (Maynard-Moody; Musheno, 2012).
A possibilidade de agência, no entanto, não opera num vácuo, mas no contexto de sistemas sociais dos quais tais agentes fazem parte (Sewell, 1992). Assim, para se compreender a racionalidade que orienta as adaptações e ações discricionárias destes agentes, torna-se relevante identificar como a formação acadêmico-profissional, na condição de um dos sistemas sociais nos quais estes agentes se inserem, orientam e dão sentido às ações no desempenho de suas funções. Tendo em vista que o ingresso e a atuação desses agentes nos Caps AD se realizam em função de suas credenciais profissionais, a formação profissional dos mesmos é fator potencialmente relevante para explicar as ações discricionárias (Evans, 2004).

A sociologia das profissões sugere três perspectivas principais para a compreensão da agência dos implementadores (Harrits, 2019). A primeira entende as profissões como comunidades morais que exercem função normativa e regulatória sobre a conduta dos seus membros, seja por meio da internalização de um código de ética típico do grupo profissional, seja por meio de mecanismos de controle por pares e organizações de classe (Abbott, 1988). A segunda perspectiva ressalta a dimensão cognitiva e as formas especializadas de conhecimento científico associadas aos grupos profissionais, adquiridas por meio da educação formal. Essa base cognitiva opera como modelo ontológico que orienta a maneira como os profissionais interpretam e intervém no mundo (Friedson, 2001). A terceira perspectiva, por fim, aborda as profissões como forma de institucionalização do poder, enfatizando seus mecanismos de monopolização de mercado, produção de status e disputas de jurisdição (Abbott, 1988; Larson, 2013). Considerando que as profissões delimitam áreas de conhecimento e de poder institucional, além de proverem normas para a ação dos membros de sua comunidade, as instituições profissionais - características das sociedades modernas - são fontes importantes de influência e condicionamento da ação discricionária dos agentes de linha de frente no setor público (Harrits, 2019).

O estudo foi orientado pela análise de narrativas e codificação de entrevistas com profissionais e observação in loco nos Caps AD do DF. Os resultados indicaram a coexistência de distintas interpretações e ações - entre esses profissionais, em torno da 
$\mathrm{RD}$, e que esta variação está fortemente associada à filiação dos nossos interlocutores a diferentes grupos profissionais e seus respectivos campos de conhecimento. Adicionalmente, nossos dados mostraram que isto tem consequências negativas para os usuários dos serviços. Os achados contribuem para reflexões mais amplas sobre os desafios que se impõem à sustentabilidade do modelo de atenção proposto para os Caps AD.

\section{Metodologia}

A pesquisa de campo foi realizada entre junho de 2018 e junho de 2019. Neste período, sete unidades de Caps AD estavam em operação no DF, distribuídas pelas regiões de saúde. Três dessas unidades (tipo III, ${ }^{3}$ com funcionamento $24 \mathrm{~h}$ ) envolviam equipes cujo tamanho variava de 57 a 8 o profissionais. Já as equipes das outras quatro unidades (tipo II) variavam de 18 a 26 membros. Em todas as unidades, a composição das equipes era multiprofissional, envolvendo assistentes sociais, psicólogos, médicos, enfermeiros, técnicos de enfermagem, terapeutas ocupacionais e, em alguns poucos casos, farmacêuticos.

A pesquisa de campo foi conduzida nas sete unidades e envolveu observações da sua operação cotidiana, participação em algumas atividades, coleta de dados objetivos sobre a gestão e entrevistas com gerentes (7) e profissionais (41). A produção de dados qualitativos, por meio de observações e entrevistas, justifica-se como estratégia de acesso às experiências dos agentes nos contextos em que desempenham seus trabalhos cotidianos na implementação dos serviços (Minayo, 2015). No que se refere aos aspectos éticos, o projeto foi aprovado pelo Comitê de Ética em Pesquisa, ${ }^{4}$ uma vez que contemplou as medidas protetivas necessárias. A estratégia de recrutamento dos participantes visou maximizar a diversidade de perfis profissionais (Trost, 1986), garantindo, no mínimo, cinco tipos de profissionais de diferentes formações em cada unidade de Caps AD estudada.

As entrevistas basearam-se em roteiro semiestruturado, contendo questões sobre a trajetória profissional (formação e experiências) e as rotinas de trabalho - práticas, atividades e percepções -, tendo duração média de uma hora. O processo de análise envolveu codificação, com suporte de software para análise de dados qualitativos (Atlas.ti 8.o), a partir de orientações da Teoria Fundamentada em Dados (Charmaz, 20o6). As entrevistas foram codificadas a partir de múltiplas rodadas de leitura. Combinou-se a codificação manual - a partir das leituras - com a codificação automática - a partir do software - de todas as menções ao termo "redução de danos" e seus correlatos. Os fragmentos das entrevistas que se relacionavam com o tema da RD foram analisados a partir do contexto mais amplo das narrativas construídas nas entrevistas, levando em consideração, também, as notas de observação em campo. Complementarmente, recorreu-se à contagem de menções e à análise de coocorrência entre códigos (Friese, 2019), visando apoiar as interpretações qualitativamente construídas com dados quantitativos sobre padrões emergentes no conjunto das entrevistas (Saldana, 2015).

\section{Resultados e discussão}

Esta seção apresenta os resultados da análise das observações e entrevistas realizadas com os profissionais. Tal como previsto pela literatura de implementação de políticas públicas, os agentes que atuam nas linhas de frente do serviço público gozam inevitavelmente de uma margem de reinterpretação das diretrizes formais (Lipsky, 1980; MaynardMoody; Musheno, 2012). Nessa direção, descreve-se, primeiramente, os achados relativos às diferentes percepções e linhas de ação adotadas pelos profissionais em relação à diretriz formal da RD. Em seguida, discutese como a presença de grupos profissionais variados nos Caps $\mathrm{AD}$ ajuda a compreender a constituição das diferenças de entendimento e atuação sobre a RD, a partir dos aportes da sociologia das profissões. Por fim, aborda-se as implicações das diferentes formas de atuação para os usuários dos serviços.

3 Portaria No 3.588, de 21 de dezembro de 2017, do Ministério da Saúde, define os tipos de unidades de Caps AD.

4 A realização da pesquisa foi aprovada pelo Comitê de Ética em Pesquisa Fundação de Ensino e Pesquisa em Ciências da Saúde (Fepecs/ SES/DF), em 22 de maio de 2018, por meio do parecer $n^{0} 2.666 .904$. 


\section{Percepções sobre redução de danos e linhas de ação adotadas na sua aplicação}

Ao longo da pesquisa de campo nos Caps AD do DF já eram perceptíveis algumas diferenças entre os profissionais no que se refere às percepções sobre a RD como orientação para o serviço. Alguns viam-na com entusiasmo e relatavam suas possibilidades terapêuticas. Outros se mostravam céticos quanto à sua efetividade, declarando-se contrários à sua utilização, mesmo reconhecendo que a adoção da $\mathrm{RD}$, naquele serviço, era uma determinação formal da Pauad. A análise das entrevistas revelou ainda um tipo de percepção intermediária, mais pragmática, segundo a qual a RD é uma orientação a ser aplicada caso a caso, a partir das demandas dos usuários e da avaliação profissional. Analisando as entrevistas junto às notas de campo, verificou-se como aqueles profissionais traduziam suas percepções sobre a RD em práticas e estratégias de cuidado, o que resultou na identificação de duas diferentes linhas de ação: "RD de escopo ampliado" e "RD como caminho para abstinência”.

\section{Redução de danos de escopo ampliado}

Esta linha de ação ancorou-se no entendimento da RD como uma estratégia que favorece a construção de vínculos entre profissionais e pacientes, ${ }^{5}$ e que envolve, necessariamente, a apropriação crescente, pelo usuário, de seus direitos de cidadania em sua aproximação com o Estado. Esta aproximação deve ocorrer pelo acesso a serviços e bens públicos - alimentação, abrigo, benefícios assistenciais, serviços de saúde etc. Ademais, a apropriação de direitos e o acesso aos serviços públicos comparecem aqui como elementos indutores de um processo mais amplo de reinserção social, de recuperação de laços e reorganização da vida. Nessa direção, o trabalho do profissional envolve (re)tecer, juntamente com o paciente, suas redes de suporte, articulando ofertas públicas de assistência e apoiando a retomada, pelo sujeito, de relações com sua família e sua comunidade. Os trechos de entrevista transcritos abaixo trazem alguns elementos que caracterizam esta linha de ação:

A redução de danos é essa aquisição. Ele vai se aproximando do próprio Estado - já que antes ele nem entrava em uma instituição pública, entende? $\varepsilon$ aí, às vezes ele consegue um benefício, um benefício mesmo da assistência, um auxílio vulnerabilidade... aívai acessando, se aproximando aos poucos. (Assistente Social Caps AD 7)

Para mim, é quando ele consegue se reinserir socialmente, porque o uso, muitas vezes, tira eles da sociedade; e eles ficam marginalizados, num mundo meio paralelo [...]. $\varepsilon$ quando eles conseguem se reinserir socialmente - às vezes até continuando o uso, mas conseguem fazer um uso mais controlado. Tem gente que chega e que fala: "eu não vou fazer uso controlado, não quero redução de danos". Beleza, então vamos trabalhar para interromper o uso mesmo. Porque, com a rede enfraquecida, eles têm dificuldade de fazer esse uso controlado [...]. Então, se você tem uma rede de apoio enfraquecida, às vezes é melhor você tentar interromper o uso mesmo. [...] Para mim, um resultado bom é formação de rede de apoio, reinserção social. (Assistente Social Caps AD 4)

Esta linha de ação supõe a ampliação do escopo das práticas mais comumente identificadas à RD como as trocas de insumos ou a redução do uso. Sob esta perspectiva ampliada, abrem-se possibilidades de ação aos profissionais que, indeterminadas a princípio, visam agregar qualidade de vida e saúde ao paciente. Aqui, mira-se para além do consumo de substâncias e das condições de uso, incluindo-se uma variedade de pequenos ganhos, os quais poderiam, cumulativamente, se sobrepor aos prejuízos, sociais e de saúde, adquiridos pelo uso problemático de drogas.

No trecho abaixo, a interlocutora explicita esta perspectiva, enquanto aponta também para equívocos que, muitas vezes, marcam a compreensão de profissionais dos Caps AD sobre redução de danos:

5 A referência aos usuários dos serviços como "pacientes", por parte dos profissionais, foi praticamente consensual. Assim, na análise das entrevistas e observações, optamos por utilizar a designação nativa. 
Eles [os profissionais] têm uma visão de que a redução de danos é reduzir droga, é reduzir o consumo. Ou mudar o consumo de uma droga mais pesada, mais danosa, para uma droga mais leve, mais tranquila. Eu não enxergo assim. A redução de danos é simplesmente a redução de danos. Então, para mim, o paciente vir ao Caps, ao invés de estar usando drogas, é uma redução de danos. O paciente continuar usando e conseguir voltar a trabalhar é uma redução de danos. o paciente conseguir viver em família.... qualquer ganho que ele tenha, com alguma ação dentro do tratamento é uma redução de danos. [...] Porque as pessoas ficam muito limitadas à redução do uso, $e$ isso vira um grande tabu. Vira um conceito rígido e fixo, que as pessoas não conseguem transcender. Redução de danos é para cada um. Não tem como eu ter um conceito único e tentar aplicar isso para todo mundo. (Psicóloga Caps AD 1)

Ao acompanhar uma reunião de equipe (no Caps AD 5), observou-se uma profissional empenhada na defesa do "direito humano de acesso à água" de um "paciente", para o qual era "técnica de referência”. Em função da situação de privação de água em seu domicílio, este "paciente" coletava água dos reservatórios do Caps e levava para sua casa. 0 caso provocou uma discussão acirrada na equipe em torno da decisão de coibir ou permitir que ele continuasse a utilizar a água do Caps. Os técnicos favoráveis à proibição entendiam que a cessão de água ao paciente não tinha nada a ver com o tratamento. A profissional que defendia a permissão, por sua vez, argumentava que, além de garantir um direito humano ao "paciente", a cessão da água contribuía para a manutenção do vínculo deste com o Caps $\mathrm{AD}$, que assim lhe prestava suporte naquela situação de vulnerabilidade. Esta controvérsia revelou a amplitude de práticas possíveis na perspectiva da RD de escopo ampliado; ao mesmo tempo, suscitou questões sobre os limites de tal perspectiva: até onde se pode avançar em nome da redução de danos?

Redução de danos como caminho para a abstinência $\mathrm{Na}$ segunda linha de ação identificada, os profissionais diziam mobilizar a RD como um meio para chegarem à abstinência dos pacientes. Neste caso, a suspensão total do uso de substâncias figura como principal objetivo e meta final do cuidado. Esse tipo de estratégia, relatado por diferentes profissionais, aparece de forma bastante evidente na fala desta médica clínica:

Na verdade, a RD é uma estratégia do tratamento. Ela não pode ser considerada meta final. $\varepsilon u$, particularmente, vejo que o ideal para o tratamento da dependência química é a abstinência, sem dúvida. O que a gente fala em cura é: ausência do uso da droga e funcionalidade. Isso seria a cura, entre aspas, dessa doença crônica. Porém, muitas vezes a gente não consegue isso. Então, a gente usa a estratégia da redução de danos. Então, a RD não é um fim, ela é um meio. (Médica Clínica Caps AD 4)

O uso instrumental da RD se justificaria pela dificuldade que alguns pacientes teriam para manter abstinência, no curto prazo. Assim, para alguns, a RD abriria possibilidades para enfrentamento desta dificuldade: "é o que dá pra fazer”. No entanto, a abstinência permanece no horizonte como o resultado mais desejável do cuidado.

A redução de danos, de distribuir seringa, distribuir para infecto, acho que não tem muita dúvida. Tem que ser feito e é muito útil, é muito bom. Mas a RD na dependência química, eu acho que às vezes ela é uma armadilha, sabe? Acho que a melhor estratégia é você pensar na abstinência como uma coisa assim: você caminha em direção à abstinência, mesmo que você nunca chegue lá. Porque é muito fácil eles começarem a usar nossos discursos de redução de danos para justificar, até para a família deles, a manutenção do comportamento. (Psiquiatra Caps AD 6)

Este depoimento reforça, ainda, um outro elemento que se mostrou saliente em várias entrevistas: o entendimento da RD no seu registro mais restritivo - isto é, como troca de insumos para o consumo seguro; como diminuição progressiva (rumo a zero) do consumo; ou como terapia 
substitutiva. O próximo comentário ilustra esta visão restrita e as possibilidades de sua tradução em ações.

Quando chega o paciente que é usuário de múltiplas drogas: foi da vontade dele continuar só com a maconha? Então já tem uma redução de danos. Depende do desejo do paciente. Se você for pensar no desejo do profissional, às vezes você fica naquela: eu gostaria que ele não usasse droga nenhuma, né? Mas, se ele já deixou o crack, se ele já está usando só maconha, se ele está tomando certos cuidados, essa redução de danos, eu acho importante sim. Para o paciente, é um ganho na vida dele. (Enfermeira Caps $\mathrm{AD}$ 2)

Em um dos Caps AD, foram acompanhadas duas sessões de um grupo terapêutico denominado "estratégias de enfrentamento", cujo objetivo era, por meio da troca de experiências entre os pacientes, discutir ferramentas para o manejo de "situações de risco" - situações que disparam, nos usuários, o desejo de consumir álcool ou outras drogas. Chamou atenção, neste grupo, a valorização de relatos em que participantes destacavam seus esforços para "resistirem às tentações" e manterem a abstinência, enquanto outros ficavam absolutamente calados diante destes relatos. Também não se ouviu, nestas sessões, nenhum depoimento que abordasse eventos de recaída, nem quaisquer sugestões ou orientações sobre como lidar com este tipo de evento. Em nenhum momento daquelas sessões foi apresentado, pelos profissionais ou pelos "pacientes", outro caminho de cuidado que não fosse o da abstinência; ou nenhuma situação em que o uso moderado ou controlado de substâncias aparecesse como possibilidade.

A linha de ação $R D$ como estratégia para a abstinência contrasta, assim, com a linha de ação anterior, pela ênfase que coloca no uso e na substância, em detrimento do sujeito e de suas demandas. Os discursos e práticas a ela associados se mostram pouco sensíveis à lógica da RD, tal como preconizada pela Pauad.

\section{Variedades de entendimentos e práticas segundo grupos profissionais}

Processos de implementação têm o potencial de transformar sentidos, métodos e até objetivos da ação governamental, uma vez que envolvem a tradução de diretrizes abstratas em ações concretas (Hill; Hupe, 2014; Pressman; Wildavsky, 1973). No caso dos Caps $\mathrm{AD}$ do $\mathrm{DF}$, a tradução do princípio da $\mathrm{RD}$, pelos profissionais, resultou em diferentes percepções e linhas de ação. Considerando que o Caps AD é um serviço caracterizado pela composição multiprofissional das equipes, a filiação de seus técnicos a categorias profissionais diversas pode contribuir para explicar como se constroem os diferentes entendimentos e práticas em RD. Por óbvio, reconhece-se que associações entre grupos profissionais e formas de ação não seguem, necessariamente, um padrão determinístico, não permitindo, portanto, explicações definitivas. Mas, tal como sugerido pela sociologia das profissões, a socialização profissional confere aos indivíduos uma base cognitiva comum (Friedson, 2001) que interfere decisivamente em sua compreensão e tradução de diretrizes gerais em práticas, seja porque os leva a fazer parte de uma comunidade moral (Abbott, 1988), seja porque favorece seu engajamento em disputas de poder e jurisdição (Larson, 2013).

A Tabela 1 fornece indícios da relação entre pertencimento a grupos profissionais e adoção de diferentes linhas de ação em RD. Primeiro, observa-se que, enquanto alguns grupos evocam o tema poucas vezes durante as entrevistas (abaixo da média geral de 2,7 ), quase se limitando às induções feitas pelos entrevistadores, outros mencionaram a RD diversas vezes (acima da referida média) ao longo das entrevistas. ${ }^{6} \mathrm{~A}$ RD foi, portanto, um tema relativamente mais presente nos discursos e reflexões de alguns tipos de profissionais - caso das(os) assistentes sociais e psicólogas(os) - do que de outros - terapeutas ocupacionais, farmacêuticas(os), médicas(os) e técnicas(os) em enfermagem.

\footnotetext{
6 A contabilização de uma menção corresponde a um fragmento de discurso (parágrafo ou conjunto de frases que expressam uma opinião) em que é abordado o termo "redução de danos" ou seus correlatos.
} 
Tabela ı - Menções e linhas de ação sobre "redução de danos" por tipos de profıssionais

\begin{tabular}{|c|c|c|c|c|c|}
\hline \multirow[b]{2}{*}{ Tipos de profissionais* } & \multirow[b]{2}{*}{$\begin{array}{c}\text { Menção } \\
\text { a RD }\end{array}$} & \multirow[b]{2}{*}{$\begin{array}{l}\text { Média por } \\
\text { entrevista }\end{array}$} & \multicolumn{2}{|c|}{ Linhas de ação em RD } & \multirow[b]{2}{*}{$\begin{array}{c}\text { Não } \\
\text { abordou } \\
\text { o tema }\end{array}$} \\
\hline & & & $\begin{array}{l}\text { RD escopo } \\
\text { ampliado }\end{array}$ & $\begin{array}{l}\text { RD caminho } \\
\text { abstinência }\end{array}$ & \\
\hline Assistência Social (8) & 27 & 3,4 & $7(100 \%)$ & $\circ(0 \%)$ & I \\
\hline Psicologia (10) & 29 & 2,9 & $6(86 \%)$ & $1(14 \%)$ & 3 \\
\hline Enfermagem (Sup.) (4) & II & 2,7 & $3(75 \%)$ & $1(25 \%)$ & 0 \\
\hline Farmácia (2) & 5 & 2,5 & $\circ(0 \%)$ & $\circ(\circ \%)$ & 2 \\
\hline Terapia Ocupacional (5) & 12 & 2,4 & $2(40 \%)$ & $3(60 \%)$ & 0 \\
\hline Enfermagem (Téc.) (8) & 19 & 2,4 & $\circ(0 \%)$ & $4(100 \%)$ & 4 \\
\hline Medicina (4) & 8 & 2,0 & $\circ(0 \%)$ & $4(100 \%)$ & 0 \\
\hline Total $(41)$ & III & 2,7 & $18(58 \%)$ & $13(42 \%)$ & 10 \\
\hline
\end{tabular}

*Nesta coluna, o número entre parênteses indica a quantidade de entrevistas realizadas em cada subgrupo.

A Tabela 1 também apresenta a associação (coocorrência de códigos) entre linhas de ação em RD e filiação profissional dos respondentes (Friese, 2019). Considerando-se o contraste entre os casos extremos (em que há concentrações acima de $85 \%$ ), 7 percebe-se que: (1) de um lado, os entendimentos e práticas identificados com a linha de ação $R D$ de escopo ampliado são claramente preponderantes nas profissões tipicamente associadas ao campo psicossocial, como a assistência social e psicologia; e (2) de outro lado, os entendimentos e práticas identificados com a linha de ação $R D$ como estratégia para abstinência são majoritários entre os técnicos de enfermagem e os profissionais de medicina, categorias tipicamente associadas ao campo biomédico.

Esses indícios remetem a um debate recorrente entre os atores do campo da Reforma Psiquiátrica, que opõe modelos terapêuticos e assistenciais em saúde mental em função dos paradigmas epistemológicos e das bases cognitivas em que se assentam. Haveria, segundo este debate, uma disputa epistemológica expressa na disjuntiva entre dois paradigmas de compreensão e tratamento dos problemas de Saúde Mental: o biomédico e psicossocial. Segundo autores que se dedicaram a formular as bases conceituais da Reforma Psiquiátrica italiana - a qual serviu de inspiração à reforma brasileira ${ }^{8}$ - a psiquiatria tradicional e suas tecnologias (ainda hegemônicas), tais como a internação hospitalar e o uso de medicamentos psicotrópicos, entre outras, estariam assentados no paradigma biomédico, herdado da medicina física, a partir do qual a loucura e os transtornos de ordem mental são interpretados como doença, "algo que está no corpo ou no psiquismo da pessoa" (Rotelli; Leonardis; Mauri, 1990, p. 27). Sendo assim, deve-se tratá-los com vistas à "cura" ou, pelo menos, à remissão dos sintomas, sobretudo por meio de medicamentos em ambiente hospitalar.

Em contraste, o paradigma psicossocial proposto pelas reformas psiquiátricas italiana e brasileira, e incorporado pelo Ministério da Saúde do Brasil, refuta a identificação entre loucura e doença, entendendo a primeira como um modo diverso e singular de se estar no mundo - ainda que sujeito a grande sofrimento. Aqui, o conceito

7 Os casos que envolvem maior grau de heterogeneidade interna aos grupos (como terapia ocupacional e profissionais de enfermagem) não permitem uma interpretação segura sobre a relação entre profissões e diferentes práticas em RD, a partir dos dados produzidos pela pesquisa. 8 Sobre as bases teórico-conceituais da Reforma Psiquiátrica italiana, ver Basaglia (2005) e Rotelli, Leonardis e Mauri (1990). Para o caso brasileiro, ver Amarante (1994, 1995) e Costa-Rosa (2000). 
de doença mental é substituído pelo de existênciasofrimento dos sujeitos, em sua relação com o corpo social (Amarante, 1994; Costa-Rosa, 20oo; Rotelli; Leonardis; Mauri, 1990). Nessa direção, a atenção psicossocial se define por levar em conta e agir sobre necessidades e demandas relativas à inserção social e comunitária dos sujeitos, sobre seus laços sociais - fragilizados ou rompidos - de modo que voltem a participar, com sua singularidade, dos circuitos de trocas que compõem o campo social.

No âmbito dos Caps $\mathrm{AD}$, a RD de escopo ampliado expressa a própria essência da atenção psicossocial, especialmente quando recusa o foco exclusivo na dependência química e na sua cura, ou na supressão dos seus sintomas (representada pela abstinência). Ao contrário, como pôde ser verificado nas citações dos profissionais na seção anterior, investe-se prioritariamente, por meio desta estratégia, na inserção social e comunitária dos sujeitos.

Considerando que os(as) profissionais criam, expõem e aplicam aos assuntos humanos os discursos das disciplinas ou campos demarcados de conhecimento e qualificação aos quais se vinculam (Friedson, 2001), não surpreende que assistentes sociais - cujo treinamento profissional é amplamente ancorado nas ciências sociais - constituam o grupo que adota com mais frequência a linha de ação RD de escopo ampliado. Do mesmo modo, parece coerente que sejam os médicos - formados a partir de uma base cognitiva biomédica - aqueles que menos o fazem, adotando com mais frequência a linha de ação $R D$ como caminho para a abstinência.

É fato que, desde que se iniciou a implementação da Reforma Psiquiátrica no país, a perspectiva psicossocial tenha sido difundida por meio de cursos de pós-graduação, como especializações e residências multiprofissionais, fazendo com que profissionais de várias formações - como psicólogos, enfermeiros, terapeutas ocupacionais, entre outros acabassem por incorporá-la às suas reflexões e práticas. Contudo, conforme revelado pelos(as) interlocutores(as), a maioria não se preparou profissionalmente para o atendimento psicossocial, ingressando nos Caps AD com base em formações onde este saber não estava presente. ${ }^{9}$

\section{Implicações e a gestão das divergências}

A variação de percepções e práticas entre grupos profissionais têm implicações importantes. Uma das mais imediatas é a emergência de divergências, tensões e conflitos no ambiente de trabalho. Foram comuns relatos sobre "arranca-rabos" entre profissionais de um mesmo Caps AD.

O diálogo abaixo revela um tipo de tensão recorrente, em torno do cuidado a pacientes em acolhimento integral. ${ }^{10} \mathrm{Na}$ perspectiva desta profissional, ainda que sob manifesta dúvida, o acolhimento integral deveria operar com base exclusivamente na abstinência. Ou seja, pacientes que pernoitam no CAPS AD devem evitar o uso de substâncias, enquanto estiverem ali, mesmo que o uso ocorra fora do equipamento. Mas este entendimento nem sempre coincide com o de seus colegas.

Os "arranca rabos" é porque, embora haja essa política, e a gente trabalhe com isso [RD], em tese, a gente tem, aqui dentro, um dispositivo de trabalho, que éo acolhimento integral, que é10o\% abstinente. Quando o paciente entra no acolhimento integral, principalmente na fase que ele está com algum tipo devulnerabilidade importante, aía lógica tem queser da abstinência. Não seise tem que ser, se deveria ser, ounão. Mas a lógica que se prega éa da abstinência.

Entrevistador: Não se permite o uso. Mas se o cara sair, vai lá, usa e volta. O que acontece com ele?

Aíéque estão os arranca-rabos que eu estou falando. Porque vai depender de quem está no plantão, vai depender de quem é o paciente, vai depender dos

9 Dentre os entrevistados, $29 \%$ relataram não ter recebido nenhuma formação em saúde mental, ou álcool e drogas, quando assumiram suas funções; $38 \%$ disseram ter recebido apenas uma formação superficial (cursos de extensão ou aperfeiçoamento) sobre esses temas; 6o\% indicaram não ter tido qualquer experiência profissional anterior no campo da saúde mental, ou dos cuidados a usuários de álcool e outras drogas. 1o Modalidade de acolhimento disponível somente nos Caps AD III, em que o paciente permanece “internado”, de forma voluntária, por até 14 dias. 
outros pacientes que ali estão. Dá uma confusão: 'por que ele pode e eu não posso?'. O tratamento a gente tenta sustentar que éindividual, no sentido de que cada pacientevai ter um projeto terapêutico. Se o seu passa poruma aceitação do uso, talvezo do outro não. Mas é difícil sustentar isso. Geralmente isso acontece em período noturno. A pessoa sai, $e$ ficou de voltar até 10 horas. Volta às 2, sob efeito. Aí o plantão não aceita. A pessoa dorme aqui fora, esperando alguém chegar, para ver se vai entrar ou não. Isso é muito corriqueiro. É uma complicação. (Terapeuta Ocupacional Caps $A D_{1}$ )

Para além de revelar as tensões e divergências entre profissionais sobre as regras do serviço, o trecho acima também é indicativo das repercussões destas divergências sobre os usuários dos serviços. O paciente em situação de acolhimento integral pode ter que dormir fora do Caps $\mathrm{AD}$ (às vezes, na rua), a depender do(a) profissional que estiver de plantão. Neste caso, divergências entre profissionais levam à prestação heterogênea de serviços, com prejuízo para o usuário. Usuários(as) com situações e demandas semelhantes podem receber atendimentos diferentes, a depender do(a) profissional com o(a) qual se relacionarem.

Incoerências entre práticas dos diferentes profissionais podem também interferir negativamente nos percursos terapêuticos dos pacientes, prejudicando a construção de vínculos e o aproveitamento das ofertas de cuidado, podendo resultar inclusive no abandono do tratamento. O relato abaixo - no qual entram em choque as posturas de uma médica e de uma assistente social -ilustra este ponto.

O grande problema da redução de danos é que você tem que ter uma equipe que banque isso, e não apenas um profissional. Hoje, eu acho que este Caps não está estruturado para oferecer redução de danos para ninguém. Porque não adianta... Um mês atrás eu fiz uma proposta de redução de danos para um paciente. A gente avançou muito. Ele tomava cinco doses diárias, foi para uma. E aí, na hora que chega na consulta médica, a médica desfez tudo o que eu falei. Falou para ele que, se não parasse [...], ela não ia conseguir mais nenhuma medicação para ele. [Mas] a gente sabe que tem medicações que não tem problema de tomar. Eaí, desfez todo o trabalho que eu fiz. Desvalorizou. Depois dessa consulta, ele falou: "não quero remédio". $E$ aí ele recaiu e foi embora... Então é assim: a RD ou você banca, ou você não banca. (Assistente Social Caps AD 5)

Ao mesmo tempo em que as divergências entre os profissionais e suas implicações ficaram bem evidentes ao longo da pesquisa, foi possível perceber, também, o importante papel desempenhado pelas gerentes e pelas reuniões de equipe. No que se refere às gerentes, percebeu-se diferença expressiva entre, de um lado os Caps $\mathrm{AD}$ que possuíam gerentes engajadas no "projeto Caps AD" e com maior tempo na função; e, de outro, as unidades que vinham passando por instabilidades na gestão. Enquanto no primeiro caso os(as) entrevistados(as) afirmavam que a atuação das gerentes contribuía para produzir alinhamento entre profissionais e mitigar os efeitos nocivos das divergências, no segundo caso atribuía-se a escalada das divergências e dos conflitos internos à ausência de uma gerência comprometida.

Um dos principais instrumentos utilizados pelas gerentes é a reunião de equipe. Em todas as unidades pesquisadas, a reunião era um encontro entre todos os profissionais e a gerência, que ocorria ao longo de uma tarde, durante a semana de trabalho. Estes encontros, além de servirem como canal de difusão de informes e discussão de questões administrativas da unidade, criavam oportunidades para a discussão de casos (pacientes) e dos problemas e desafios emergentes. Foi possível acompanhar diversas dessas reuniões e constatar seu potencial de transformar as divergências práticas derivadas do multiprofissionalismo em entendimentos compartilhados; e no alinhamento da atuação dos profissionais em torno de casos concretos. Tratava-se de um mecanismo que permitia a explicitação dos conflitos em ambiente propício para produção de resoluções coletivas e para a construção de consensos.

0 relato abaixo, de uma profissional veterana, articulou os elementos apontados acima, situando-os em perspectiva temporal, com foco no desenvolvimento gradual da sua equipe.

Existem divergências de pensamento. Mas como eu estou aqui desde o início, eu acho que já existiu 
muito mais. A gente teve uma fase que a equipe foi muito conflituosa. A gente teve um gerente que muitos amaram e muitos mais odiaram, mas ele era uma pessoa muito boa teoricamente. Eele acabou forçando as pessoas a fazerem estudos e a refletirem sobre questões de redução de danos, de reforma psiquiátrica e tal. Durante muitos anos, toda quinta-feira ele batia isso na nossa cabeça, em todo estudo de caso. Eu acho que isso deu uma uniformizada, minimamente, no pensamento. Não que não tenha divergência, tem muita divergência, mas eu acredito que a nossa equipe amadureceu nesse sentido. (Psicóloga Caps $\mathrm{AD}$ 5)

\section{Considerações finais}

Este artigo examinou o funcionamento das equipes multiprofissionais que atuam nos Caps $\mathrm{AD}$ do Distrito Federal, no que se refere à implementação da diretriz de Redução de Danos, contida da Política do Ministério da Saúde, instituída no início dos anos 200o. Segundo o documento que apresenta esta política, a decisão de dotar estes serviços de equipes integradas por profissionais de múltiplas formações se deu sob a premissa de que intercâmbios de saberes e práticas diversos são imprescindíveis para a efetivação do modelo de atenção psicossocial, que visaria ao cuidado integral dos usuários.

A análise desenvolvida procurou compreender implicações práticas do multiprofissionalismo no funcionamento cotidiano destes serviços, discutindo variações nos entendimentos e práticas em relação à RD. Os resultados indicaram que as profissões cuja formação envolve disciplinas do campo psicossocial como assistentes sociais e psicólogos - tendem a conceber e exercer uma redução de danos de escopo ampliado. Já as profissões cuja formação enfatiza as ciências do campo biomédico tendem a interpretar e praticar a RD como uma estratégia, um meio ou instrumento para alcançar o objetivo último da abstinência - como cura ou mitigação dos sintomas de uma doença. Tal como previsto no debate teórico sobre profissões, os alinhamentos identificados podem estar associados às diferentes bases cognitivas, comunitárias e institucionais nas quais foram previamente socializados os distintos grupos profissionais, atuantes nos Caps AD.
Além disso, a pesquisa constatou que as diferenças observadas entre os grupos profissionais podem se expressar em termos de divergências, tensões e conflitos, com efeitos negativos para os usuários atendidos, tais como prejuízos a sua vinculação aos planos terapêuticos propostos. Em relação a estas divergências, identificou-se também mecanismos - como a atuação das gerências e as reuniões de equipe - que contribuem para a gestão do multiprofissionalismo, de modo a mitigar suas implicações perturbadoras e fortalecer as potencialidades de articulação de distintos saberes na abordagem da complexidade dos problemas decorrentes do uso de álcool e outras drogas.

\section{Referências}

ABBOTT, A. The system of professions: an essay on the division of expert labor. Chicago: University of Chicago Press, 1988.

AMARANTE, P. Uma aventura no manicômio: a trajetória de Franco Basaglia. História, Ciências, Saúde, Manguinhos, v. 1, n. 1, p. 61-77, 1994.

AMARANTE, P. (Org.). Loucos pela vida: a trajetória da reforma psiquiátrica no Brasil. Rio de Janeiro: Editora Fiocruz, 1995.

BASAGLIA, F. Escritos selecionados em saúde mental e reforma psiquiátrica. Rio de Janeiro: Garamond, 2005.

BRASIL. Lei n ${ }^{0} 10.216$, de 6 de abril de 2001. Dispõe sobre a proteção e os direitos das pessoas portadoras de transtornos mentais e redireciona o modelo assistencial em saúde mental. Diário Oficial da República Federativa do Brasil, Brasília, DF, 7 abr. 2001. Disponível em: <https://bit.ly/3qEYzHK>. Acesso em: 17 jan. 2019.

BRASIL. Ministério da Saúde. A política do Ministério da Saúde para a atenção integral a usuários de álcool e outras drogas. Brasília, DF, 2004.

BRASIL. Ministério da Saúde. Portaria n ${ }^{0}$ 3.088, de 23 de dezembro de 2011. Institui a Rede de Atenção Psicossocial para pessoas com sofrimento ou transtorno mental e com necessidades decorrentes do uso de crack, álcool e outras drogas, no âmbito 
do Sistema Único de Saúde (SUS). Diário Oficial da União, Brasília, DF, 26 dez. 2011. Seção 1.

CHARMAZ, K. Constructing grounded theory: a practical guide through qualitative analysis. London: Sage, 2006.

COSTA-ROSA, A. O modo psicossocial: um paradigma das práticas substitutivas ao modo asilar. In: AMARANTE, P. Ensaios: subjetividade, saúde mental, sociedade. Rio de Janeiro: Editora Fiocruz, 200o. p. 141-168.

EVANS, T. Professional, managers, and discretion: critiquing street-level bureaucracy. The British Journal of Social Work, Londres, n. 34, p. 871-895, 2004.

FERREIRA, I. F. R. O paradigma da redução de danos na clínica com usuários de drogas: inflexões, deslocamentos e possibilidades de escuta e posicionamento clínico. Boletim de Análise Político Institucional, Brasília, DF, n. 18, p. 71-79, 2018.

FRIEDSON, E. Professionalism: the third logic. Cambridge: Polity Press, 2001.

FRIESE, S. Qualitative Data Analysis with ATLAS.ti. Londres: Sage, 2019.

HARRITS, G. Street-level bureaucracy research and professionalism. In: HUPE, P. Research handbook on street-level bureaucracy. Cheltenham: Edward Elgar, 2019. p. 193-208.

HILL, M.; HUPE, P. Implementing public policy: an introduction to the study of operational governance. London: Sage, 2014.

LARSON, M. S. The rise of professionalism: monopolies of competence and sheltered markets. New Bunswick: Transaction, 2013.
LIPSKY, M. Street-level bureaucracy: dilemmas of the individual in public services. New York: Russell Sage Foundation, 1980.

MAYNARD-MOODY, S.; MUSHENO, M. Social equities and inequities in practice: street-level workers as agents and pragmatists. Public Administration Review, Washington, DC, v. 72, p. S16-S23, 2012. Suplemento 1.

MINAYO, M. C. S. O desafio do conhecimento: pesquisa qualitativa em saúde. São Paulo: Hucitec, 2015.

PETUCO, D. R. S. Redução de danos: das técnicas à ética do cuidado. In: RAMMINGER, T.; SILVA, M. Mais substâncias para o trabalho em saúde com usuários de drogas. Porto Alegre: Rede Unida, 2014. p. 133-148.

PRESSMAN, J.; WILDAVSKY, A. Implementation. Berkeley: University of California Press, 1973.

ROTELLI, F.; LEONARDIS, O.; MAURI, D.

Desinstitucionalização, uma outra via: a reforma psiquiátrica italiana no contexto da Europa Ocidental e dos países avançados. In: NICÁCIO, F. Desinstitucionalização. São Paulo: Hucitec, 1990. p. 27-59.

SALDANA, J. The coding manual for qualitative researchers. London: Sage, 2015.

SEWELL, W. A. Theory of structure: duality, agency, and transformation. American Journal of Sociology, Chicago, v. 98, n. 1, p. 1-29, 1992.

TROST, J. E. Statistically non-representative stratified sampling: a sampling technique for qualitative studies. Qualitative Sociology, Evanston, v. 9, n. 1, p. 54-57, 1986.

\section{Contribuição dos autores}

Pires e Santos analisaram e interpretaram os dados, redigiram o artigo, atuaram conjuntamente na revisão e na aprovação da versão a ser publicada.

Recebido: 04/08/2020

Reapresentado: 09/12/2020

Aprovado: 06/01/2021 